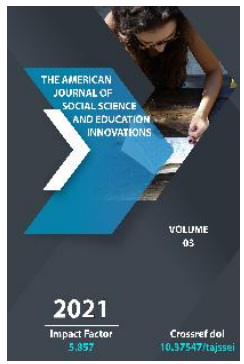

\title{
Law Of Negation In Linguistics
}

Keldiyorova G.S.

Associate Professor, National University Of Uzbekistan, Tashkent, Uzbekistan

Journal Website:

http://usajournalshub.c om/index,php/tajssei

Copyright: Original content from this work may be used under the terms of the creative commons attributes 4.0 licence.

\section{ABSTRACT}

This article examines the issues of antonymy and antithesis, oxymoron, and also analyzes the logicalphilosophical category of opposition and its linguistic reflection. Antithesis is viewed as a combination of mutually contradictory statements about objects and phenomena of reality, implying antonymy in linguistics.

\section{KEYWORDS}

Opposition, contradiction, opposition, similarity, opposition , oxymoron, denial , expression , emotionality .

\section{INTRODUCTION}

Thoughts about antitheses have been around since antiquity. Aristotle drew attention to the syntactic structure of the antithesis: "The antithetical period is a period in which a contradiction in one of two parts stands next to the second one, or one contradiction joins the second negation. With this method of presentation, it is extremely easy to understand the contradictions, if they stand side by side, they are pleasant because they are 
even more understandable, and this method is similar to a syllogism, because proof is a comparison of contradictions. " Other ancient scholars also expressed their thoughts on the logical aspects of the antithesis and pointed out that a phrase that contradicts the first phrase logically comes from that phrase.

The contrast principle is a complex and multifunctional phenomenon. It has scientific grounds and is considered in such sciences as philosophy, logic, aesthetics, psychology, sociology, painting, music, marketing, literary criticism. The principle of contrast is actively involved in our daily life: in interior decoration, buying things, advertising goods, etc.

The figure of contrast also plays an important role in language systems, regardless of which group the languages belong to, whether they are related, dead, or modern.

Contrast is closely related to concepts such as opposition, contradiction, opposition, similarity, opposition. According to Ferdinand de Saussure "Language is a system, solely based on the anti - posed its concrete units" and "the whole linguistic mechanism revolves solely around identities and differences" .

A diverse system of artistic means, which is a direct reflection of a person's cognition of the world through the ratio of opposites, allows us to talk about the poetics of contrast.

Linguists who touch upon the problem of contrast in their works agree on its two-term structure. The contrast is "the stylistic principle of the development of speech, which consists in the dynamic opposition of two contentlogical, as well as structural-stylistic plans of presentation"
The term "contrast" received a very broad interpretation in linguistics and was considered both as a kind of opposition, and as a compositional-stylistic principle of speech development, and as one of the principles of "advancement", and as a principle of text organization. Such a broad consideration led to the variety of definitions of contrast. Contrast in a literary text covers different levels of its structure, arranges and organizes the text. It can manifest itself both at the phonetic, morphological, lexical and syntactic levels of the text as one of the types of its semantic and stylistic organization.

Being, of course, a complex and multifaceted phenomenon, the contrast has been interpreted in different humanitarian areas of human knowledge. Depending on the field of study, it is considered in its own way. Ideas about the antithesis in the world and the individual linguistics are reflected in the scientific works of such scientists as Sh.Balli, IV Arnold, I.R.Galperin, V.Vinogradov, A.I.Efimov, A.N. Grozdev, I.B. Golub [5].

In matters of describing the antithesis, the opinions of linguists generally do not differ from each other $[1,2,3]$.

The law of negation by negation in philosophy was originally set forth by Hegel. According to him, the original whole thought (thesis) is divided into two thoughts, consisting of positive and negative "yes" and "no", contradicting each other. Dividing the whole into two parts is an antithesis, a negation. At the end of the struggle, opposite thoughts unite and form a new thought (synthesis, negation of negation).

Farabi's views on opposites (antonyms) are of particular important. He wrote as followings: "The essence of each contradiction is such that 
regardless of the location of one of them, the absence of the first presupposes the presence of the second one" [6].

In the appearance of the antithesis, the logical and spiritual state are important. This shows the relationship of logic and psyche with the language. If the concept as a logical category is formed on the basis of linguistic materials, then the meaning of the word develops in conjunction with the concept. The greatest attention was paid to opposition in connection with the development of various problems of antonymy, as well as in the classification of opposition types at the level of the phonetic composition of the language, however, the results obtained are not always applicable to oppositions arising at the level of more complex linguistic and speech structures.

In Russian linguistics, there are articles and scientific works devoted to the antithesis. In particular, LA Vvedenskaya, along with such phenomena as oxymoron, acrosthesis, widely studied antithesis [2]. If the scientist Ya.I. Gelblu, who studied the antonyms of the German language, investigated them from the point of view of the relationship between antonyms and antitheses, then I.V. Dmitrevskaya investigated contradictory concepts in thinking. The scientist emphasized antonyms as a linguistic means, revealing the opposite concepts of thinking [4]. And G.M. Belova, on the basis of the materials of the French language, reflected on the linguistic means that reveal the antithesis [3]. MS Kaplan also substantiated her ideas on the use of antonyms in the stylistics and linguistic tasks of the antithesis [5].

L.A. Vvedenskaya and L.G. Pavlova believed that "to revive speech, to give it emotionality, expressiveness, imagery, it is necessary to use the antithesis." "This method, based on the comparison of opposite phenomena and signs, is considered an antithesis: the main quality of this figure is that the two parts of the antithesis illuminate each other, and is also expressed in a short form, which makes it possible to enhance its expressiveness" [2].

The specialist in the stylistics of the English language I.R.Galperin expressed the peculiarities of the antithesis as follows: "Antithesis is a contiguous phenomenon between stylistics and logic."

The Swiss linguist S. Bally gives the following assessment: "A vivid manifestation of the exact expression and decoration of the natural directions of the methodological means of speech is an antithesis."

Obviously, in all the statements of these scientists, the general properties of the phenomenon of antithesis were investigated.

LA Matvievskaya divides antitheses into 2 types: "in the first antithesis, the opposite of various phenomena is expressed with the help of antonyms.

Its meaning is manifested in the unity of the following; a) comparison of two objects or phenomena; b) show the contradictions between them from the point of view of this relationship; c) the presence of opposites in these two objects or phenomena [2]. It is in this case that a pure (conditionally) and textual antithesis can be distinguished. In particular, antitheses that are reflected through readymade means that serve to form a special antithesis existing in the language, that is, antitheses that appeared on the basis of antonyms, can be evaluated as simple antitheses. And antitheses that do not exist in the language in finished form as antonyms and 
are formed only in speech conditions with the help of specially contradictory means can be evaluated as textual antitheses. The antithesis of one pair of oppositions: The strong is always guilty of the powerless. And complex, when several antonymic pairs are involved in the figure at once. In the use of antonyms, it gives additional expression to speech, makes the phrase aphoristic precisely due to the duality, the collision of opposites. It is no coincidence that antonymy underlies many famous aphorisms: Houses are new, but prejudices are old. The darker the night, the brighter the stars. The use of an antithesis can be an original move in the title of a novel or a book, according to this principle, many titles of famous works are built ("War and Peace" by Leo Tolstoy, "The Prince and the Pauper " T Vienna and ). Oppositions are also one of the favorite tools of journalists and publicists, using antithesis in loud and provocative headlines. Thus, we see that authors, regardless of what they write - an article or a serious novel, can use the antithesis to attract the reader's attention, to give the phrase ambiguity and aphorism. The principle of opposition remarkably enhances the expression and emotionality of a phrase. And this must be used.

A. Mamadjanov, who studied the functions of antithesis in a complex sentence in Uzbek linguistics, its originality, linguistic and speech units, with the help of which they are formed, expressed his ideas as followingly: In order to enhance expressiveness in speech, contradictory concepts are used - the method of comparison - contradicting each other in terms of content through opposing thoughts. And this method is called antithesis. In the modern Uzbek literary language, this method is used very widely.
The main task of the antithesis is contrast. On the basis of semantic contrast, as a result of the opposition of speech units with a special syntactic structure, the phenomenon of antithesis is formed. These ideas confirm the above views on textual and pure antitheses. A. Mamadzhanov also pointed out the linguistic and speech units that are the material of the antithesis, and the scientist also dwelled on the type of antithesis, called chiasm, which is found mainly in complex sentences.

In Russian linguistics, it is noted that from the fusion of chiasm and antithesis, antimetabol appears .

In R. Kungurov's book, this concept is explained as follows: "Antithesis from the Greek word antithesis - opposition. Antithesis is considered one of the phenomena of poetic syntax. In speech, it is a comparison of opposite concepts, thoughts, images, objects and characters of individuals from a logical point of view to enhance expressiveness, or it is an image of the opposite state of only one object or phenomenon from the point of view of the level. In our classical literature, antithesis is called "tazod" (antithesis, opposite)".

The scholarly literary critic T. Babaev writes in the brochure "Shear IImi Talimi": sources, then in "tazod" they have a single source."

The author observes the differences between them from this side and argues from the same point of view.

The scholarly literary critic Y. Iskhakov gives the following definition: "Tazod is the use of words or expressions denoting conflicting concepts in poetry or prose from the point of view of a certain attitude." 
The pamphlet of Abdurauf Fitrat "Literary Rules", published in 1926, is of great theoretical and practical importance. In his words, "The masterful fusion of two opposing thoughts with each other is called the 'opposite'."

N. Mallaev made an interesting idea about this: "According to the requirements of the" tazod "method, two opposite poles (image, concept, physical body, process, etc.) must deny each other. But at the same time, in many cases, there is some kind of internal or external connection between the two opposing poles".

Many scientists use the term in its antithesis extended interpretation, combining linguistic, logical and literary understanding of the antithesis, using words and opposition of the antithesis as synonyms. Antithesis is a particular case of realizing opposition, a stylistic device of actualized opposition of opposites, which is realized in a "small" context (sentence, phrase) and differs from other stylistic figures based on opposition. Antithesis is a form of the most obvious, demonstratively highlighted opposition, a kind of standard of syntagmatic arrangement of this type of relationship.

Despite the large number of studies of this phenomenon, it seems to us that the analysis of contrast has not lost its relevance and novelty due to the fact that, firstly, there are many large and small literary works (including the story that will be discussed in this article ), which did not come to the attention of specialists, and, secondly, it continues to be a popular technique in modern literature and, as a result, is continuously developing, evolving and acquiring new interesting features and characteristics.

So the antithesis is opposition. This type of art is used to compare opposing concepts, thoughts, images, phenomena, personalities to enhance expressiveness. Antithesis is used as an important poetic tool in poetry. In it, the two opposite poles deny each other, basically imply the opposite of views. In order to understand, to feel this, it is important for the listener to pay attention to contradictory things and phenomena. It is advisable to perceive antithesis and tazod as the same phenomenon and their names are taken from the Greek and Arabic languages.

In their work, to enhance the imagery and expressiveness of speech, writers use special means called stylistic figures. A figure is an unusual structure of a sentence or a turn of speech, a special syntactic design of a phrase.

It should be noted that the antithesis is distinguished by the fact that it, as a speech phenomenon, appears and is formed with the participation of various linguistic units.

Based on the above, we can come to the conclusion that the concept of opposition in Western literature is seen as an antithesis, and in the eastern as a tazod.

Opposition is closely connected with the most important law of the development of being, cognition and thinking - the law of the unity and struggle of opposites. These multidirectional ways of the existence of opposites received their stylistic expression not only in the reception of the antithesis, but also in the oxymoron (Greek oxymoron - wittystupid): the absolutization of the struggle, the mutual exclusion of the polar sides constitute the meaningful invariant of the antithesis, and the internal unity and interpenetration of opposites are at the heart of the oxymoron. "Oxymoron is a stylistic figure, which is a combination of incompatible, opposite in meaning words, figuratively revealed in the 
designated mutually exclusive and contradictory beginnings" [2, p. 25].

If the antithesis contrasts antonymic concepts, then the oxymoron, on the contrary, brings them together, thereby creating an expressive contradiction. The formation of an oxymoron is based on the "principle of expedient incompatibility", which creates an aesthetic effect of expressiveness in oratory.

\section{REFERENCES}

1. Belova G.M. Linguistic means of expressing the antithesis. Abstract of the thesis . $d$ iss .. cand. philological Sciences M. 1970.

2. Vvedenskaya L.A. Stylistic figures based on antonyms. Scientific notes of the Kursk state. pedagogical institute. -Kursk. 1966. № 25-c.128-138.

3. Gelblu Ya.I. Antonymy and antithesis . In the chennye notes of the Bashkir University. Con . UFA, 1964, pp. 153-159.

4. Dmitrevskaya I.V. To the question of contradictory and progivopodic concepts. I Logical and grammatical sketches. Moscow: 1961.

5. Kaplan M.S. Objective properties of antonyms in stylistic use and the function of antithesis. Questions of theory and methods of teaching foreign languages. Issue 1 - Kazan. 1966.

6. Tulenov J., Fofurov S. Falsafa. - Tashkent: Kituvchi. 1991.219-p. 215-p.

7. Gavrilova ES Linguistic expression of opposition. Bulletin of the Kostroma State University. ON. Nekrasov . 2013 No. 3. p. 141-144. 